\title{
Towards a Model of Online Petition Signing Dynamics on the Join Platform in Taiwan
}

\author{
Huang, Hsin-Ying ; Kovacs, Mate ; Kryssanov, Victor ; Serdült, Uwe
}

\begin{abstract}
Since 2015 all citizens in Taiwan and since 2018 also residents can use the online platform called "Join". The platform allows registered users to propose, discuss and review governmental policies. The ongoing practice currently makes Join one of the most innovative and successful cases of digital policy co-creation worldwide. However, due to the language barrier little is known about its contents. Internationally available research results are scarce. This article provides an overview of the platform's functionalities as well as an overview of the research published to date. In addition, a first descriptive inroad to online petition dynamics is made. The case studies are based on the dataset available on the government's Open Data portal. The goal of this paper is to lay the groundwork and provide the context for a more comprehensive quantitative analysis of online petition signing dynamics in Taiwan.
\end{abstract}

DOI: https://doi.org/10.1109/icedeg52154.2021.9530852

Posted at the Zurich Open Repository and Archive, University of Zurich

ZORA URL: https://doi.org/10.5167/uzh-209092

Conference or Workshop Item

Accepted Version

Originally published at:

Huang, Hsin-Ying; Kovacs, Mate; Kryssanov, Victor; Serdült, Uwe (2021). Towards a Model of Online Petition Signing Dynamics on the Join Platform in Taiwan. In: 2021 Eighth International Conference on eDemocracy eGovernment (ICEDEG), Quito, Ecuador, 28 July 2021 - 30 July 2021. IEEE, 199-204.

DOI: https://doi.org/10.1109/icedeg52154.2021.9530852 


\section{Towards a Model of Online Petition Signing Dynamics on the Join Platform in Taiwan}

\author{
Huang Hsin-Ying ${ }^{1}$ \\ ${ }^{1}$ College of Information Science and Engineering \\ Ritsumeikan University \\ Kusatsu, Japan \\ is0483ei@ed.ritsumei.ac.jp \\ Kryssanov Victor ${ }^{1}$ \\ ${ }^{1}$ College of Information Science and Engineering \\ Ritsumeikan University \\ Kusatsu, Japan \\ kvvictor@is.ritsumei.ac.jp
}

\author{
Kovacs Mate ${ }^{1}$ \\ ${ }^{1}$ College of Information Science and Engineering \\ Ritsumeikan University \\ Kusatsu, Japan \\ kovacsm@fc.ritsumei.ac.jp \\ orcid no: 0000-0001-5999-8061 \\ Serdült Uwe $\mathrm{Uw}^{1,2}$ \\ ${ }^{2}$ Centre for Democracy Studies Aarau (ZDA) \\ University of Zurich \\ Aarau, Switzerland \\ uwe.serdult@zda.uzh.ch \\ orcid no: 0000-0002-2383-3158
}

\begin{abstract}
Since 2015 all citizens in Taiwan and since 2018 also residents can use the online platform called "Join". The platform allows registered users to propose, discuss and review governmental policies. The ongoing practice currently makes Join one of the most innovative and successful cases of digital policy co-creation worldwide. However, due to the language barrier little is known about its contents. Internationally available research results are scarce. This article provides an overview of the platform's functionalities as well as an overview of the research published to date. In addition, a first descriptive inroad to online petition dynamics is made. The case studies are based on the dataset available on the government's Open Data portal. The goal of this paper is to lay the groundwork and provide the context for a more comprehensive quantitative analysis of online petition signing dynamics in Taiwan.

Index Terms-crowd-sourcing legislation, online petition, epetition, petition dynamics, digital governance, smart city governance
\end{abstract}

\section{INTRODUCTION}

Information and communication technologies offer a wide range of opportunities not only to transform traditional oneto-one interactions between humans into digital extensions thereof, allowing for many-to-many interactions on a broad scale, but also to create new forms of governance. Governments across the globe, especially in large urban areas, are rethinking how to interact with citizens, harnessing the wisdom of the crowd. One such digital tool gaining popularity are online petitions. They allow for the creation of ideas or policy proposals in a bottom-up process and to be heard by governments, ultimately in order to improve service delivery and quality of living. Online petitions exist in manifold variants and degrees of consequences they can have for governments, organized stakeholders and individuals alike [1], [2]. While 978-1-6654-2512-4/21/\$31.00 @ 2021 IEEE some have a mere agenda-setting function, others lead directly into a political process of law making.

With the European Citizens' Initiative (ECI), for example, it is possible for one million signatories from at least seven EU countries to bring a concern from the population directly to the EU commissions [3]. Before the collection of signatures can begin, the initiative must be registered by the organizers with the EU Commission. The EU Commission is obliged to respond to the petition, but not compelled to implement it. The ECI is therefore a relatively weak instrument with little substantive consequences.

In Finland, a national people's right has emerged with the adoption and implementation of the Citizens' Initiative Act of January 13, 2012 [4]. The new law includes the right to launch a 'legislative initiative' addressed to the Parliament. Finnish citizens must register for this purpose with their name, date of birth and place of residence on the website 'Open Ministry'. The website is operated by the Ministry of Justice. To be considered by Parliament, a bill must gather 50,000 signatures within six months. It is possible to introduce a new law, amend or abolish existing laws. However, once an initiative has been introduced, Parliament is free to accept a proposal only in part or not at all. In principle, initiatives are treated in the same way as regular bills (including consideration in committees, hearing of experts, consideration in the plenary).

In Germany, the e-petition process is rather formalized [5]. The option of online petitions was introduced in 2005 and was based on the Scottish model and software. A distinction must be made between individual and public petitions, both of which can be submitted exclusively via a corresponding form on the parliament's own website. Each petition is examined by the parliamentary petitions committee to ensure that everything is formally correct and its content is appropriate. In order to qualify as a public petition 50,000 signatures within four 
months are needed. Each petition request is also answered by the authorities and, if necessary, submitted to the Petitions Committee of the Bundestag for consultation, in which the petitioner is heard in person.

In response to the fast development of information and communication technologies, digital governance has also become one of the most popular topics for the Taiwanese government [6]. Lately, the Taiwanese government has become more committed to use technology applications for policymaking, for example via e-petitions. To enhance communication effectiveness between the Taiwanese government and its citizens a public policy participation platform called "Join" (https://join.gov.tw/) was established in 2015. It allows citizens and residents to propose policies as well as to consult and monitor public administration.

In this article, the goal is to first get an understanding of functionalities offered on the Join platform and then focus on the policy proposal mechanism geared towards bringing up topics in a bottom-up process by the general public and addressing them towards the public administration. A first glance at online petition signing patterns over time allows to gain a qualitative look at the content and patterns of some of the successful cases on the Join platform.

\section{Join PlatForm FunCtionalities}

The focus for this paper is the online petition function on Join. However, the Join platform in Taiwan is more comprehensive, includes digital instruments for public consultation and co-creation, discussion, monitoring as well as participatory budgeting (see Fig. 1).

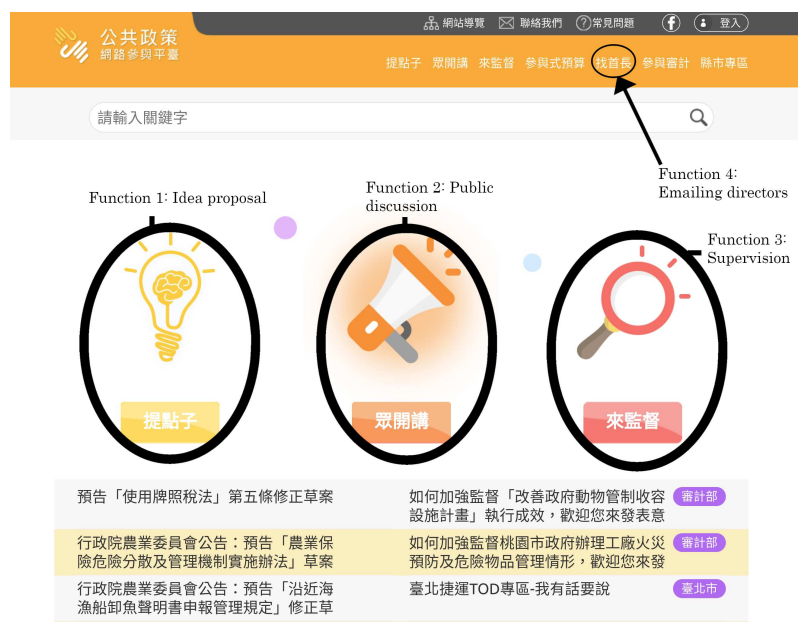

Fig. 1. User Interface of the Join platform.

Referring to the US White House website "We The People", the Taiwanese government had implemented the "Idea Proposal" function in September 2015. It allows both Taiwanese nationals and since 2018 also foreigners who are living in Taiwan to make policy proposals in the form of an online petition to the national public administration. The proposal mechanism of the Join platform includes five procedural steps, including proposer authentication, the submission of the proposal, verification by authorities, support by the general public and a response by a governmental office. In order to endorse a proposal an account on the platform is needed. People can log into the Join platform with social media accounts such as Facebook, Google, or Yahoo. After twofactor authentication with both mobile phones and emails, citizens can make proposals regarding public policies within the operational scope of the Executive and its agencies at all levels. Before a proposal can be opened up for supporting votes by the general public, it is evaluated by the public administration, checking for consistency and appropriateness. The phase during which a proposal stays on the platform to collect votes of secondment by the public was set to 60 days. Once the period of 60 days is over and a minimum of 5,000 seconding votes collected, the government will give an official response within two months. When the platform was first established, the voting threshold was different. The initial procedure included two phases; when a person made a proposal on the platform, 250 signatures within the first 15 days had to be obtained to go ahead to the second phase, in which the proposal had to reach 5,000 signatures within the next 30 days [7], [8]. Later on, to make the system more user friendly, the National Development Council of Taiwan simplified the procedure to one stage only, applying the upper mentioned thresholds for time and number of supporting votes. The idea proposal function is open except in the event of an upcoming national or local election, in which case it will be suspended for 60 days prior to that election (previously 75 days, rule changed in April 2018).

\section{RELATED WORK}

Digital democracy research in Taiwan has dealt with almost the whole spectrum of the domain. However, for the purpose of this paper the focus of this brief literature survey is exclusively on research related to the Join platform.

\section{A. E-petition Content Analysis}

In this governmental report, successful proposal data submitted between August 2016 and December 2017 was collected to be further categorized and analyzed with the help of content analysis. Also, semi-structured interviews with representatives from several governmental offices and agencies were conducted [9].

Looking into the characteristics of past successful proposals and applying a well-known policy typology mainly used in political science, four main proposal categories were distinguished: regulatory policy, distributive policy, self-regulation policy, and re-distributive policy; the percentage of proposal categories addressed above are $83 \%, 9 \%, 5 \%$, and 3\%, respectively, with regulatory policy largely dominating. The establishment of the Join platform not only allows citizens to become more active in proposing ideas for public policy discussion, but also provides government officials with a channel to collect ideas from them and pass on information. Various government offices have provided their views regarding the Join platform. According to the report, the Join platform has 
enhanced communication and trust between the Taiwanese government and its citizens. After reviewing the operating mechanism and service functions of the Join platform based on suggestions from the users, it is believed that while online petitions can bring positive attitudes towards policy discussion, there is still a lot to improve regarding the quality of online discussions, topic selection and supporting user diversity. Moreover, to eliminate the problem of vague proposal content, the Taiwanese government set guidelines for users wishing to launch a petition.

\section{B. Join Platform User Survey}

Active Join platform users were randomly selected via email and phone messages for an online survey that took place on two separate dates in September 2018. The goal of the survey was to find out about user characteristics and to understand how users experienced the platform. The response rates for platform users contacted via emails and phone messages were $2.3 \%$ and $2.7 \%$, respectively [10].

According to the survey, platform members who participate in public policy discussions are often highly educated males. However, the gender ratio of platform members has become more equal recently. The survey also shows substantial differences in age composition and educational level among platform users. The majority of the users are between 20 to 39 years old and have obtained a bachelor's degree or above, which means the Join platform mostly reflects ideas from the young educated generation being more familiar with technology.

Although the Join platform was established in 2015, there are still many people in Taiwan who do not know about it. Regarding the channels through which users initially get information about the platform, well over half $(61.3 \%)$ of the current platform members learn about the Join platform through social networking sites. Approximately 9\% of the respondents did research on their own about a topic of interest and discovered the platform. In addition, about another $9 \%$ of the platform users participating in the survey learned about Join from relatives, friends, or colleagues and $8.5 \%$ through television news [10].

Among the four functions offered on Join, "Idea Proposal" has the highest participation rate with $29.5 \%$, followed by $14.3 \%$ for discussion/seconding and $16.2 \%$ for supervising. When using the platform, approximately $36 \%$ of the participants leave the platform after expressing their opinions based on a specific topic, with only $9.5 \%$ who tend to explore other functions on the Join platform as well. As the public policy discussion platform provides users with an option to subscribe to issues of interest, $38.1 \%$ of the members often go back to the platform to track the progress of the issues they are interested in. As for the motivation of participating in the discussion of the proposals, most of the members only engage in the discussion if they directly affect their daily lives. A small percentage of participants joins the voting procedure of proposals just because the proposals are very close to reaching the threshold of 5,000 votes [10].
According to the participation platform survey, $41 \%$ of members believe that the platform has an influence on the government's decision-making processes, but only $15.1 \%$ feel their trust in government was increased by using the platform.

\section{Join Proposal Open DATA}

In this paper, two types of Join platform data were used for a first descriptive analysis of petition activity.

One is a monthly updated, aggregated open dataset of all proposals from September, 2015, containing information about the petitions such as submission date, title, number of supporters, etc. Removing petitions when the supporter threshold was not yet set to 5,000 (in the initial stages of the platform in 2015 and 2016) resulted in 9,729 proposals from the data retrieved on March 12, 2021 (see: https://data.gov.tw/dataset/58036). The general characteristics of the proposal data are shown in Fig. 2. A large amount of proposals, almost half, did not survive the verification stage. Over time, proposals that did not fulfill the formal requirements peaked in late 2017, early 2018 (see Fig. 3). That also shows the proposal frequency of the original v. the preprocessed dataset. Governmental guidelines on how petitions can be accepted might have alleviated the situation. However, petitions not entering the signature collection stage are still relatively frequent.

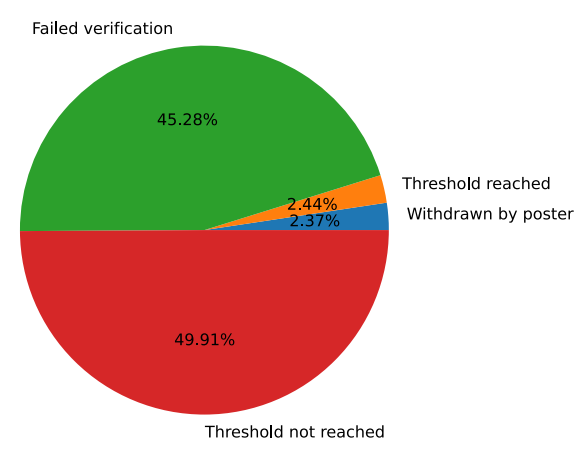

Fig. 2. General characteristics of the Join Proposal Open Data.

Preprocessing the dataset by keeping only the proposals which went through during the 60 days voting period (i.e., passed verification and were not withdrawn) resulted in a total of 5,074 petitions.

Table I presents additional statistics on the preprocessed data, showing the differences between petitions interrupted by elections vs. "normal" petitions. The empirical evidence presented here indicates that in order to be successful with a petition on the Join platform, it should rather not be launched close to an election date. Due to this interruption, the chances of passing the threshold of 5,000 supporting votes are much lower than in normal times. The percentage of petitions of almost 5\% reaching the threshold seems low at first sight. However, this means that on average about 3.5 petitions made the threshold every single month since Join was in operation.

Fig. 4 shows the number of supporters per petition on a logarithmic scale. Displaying a heavily tailed distribution, 


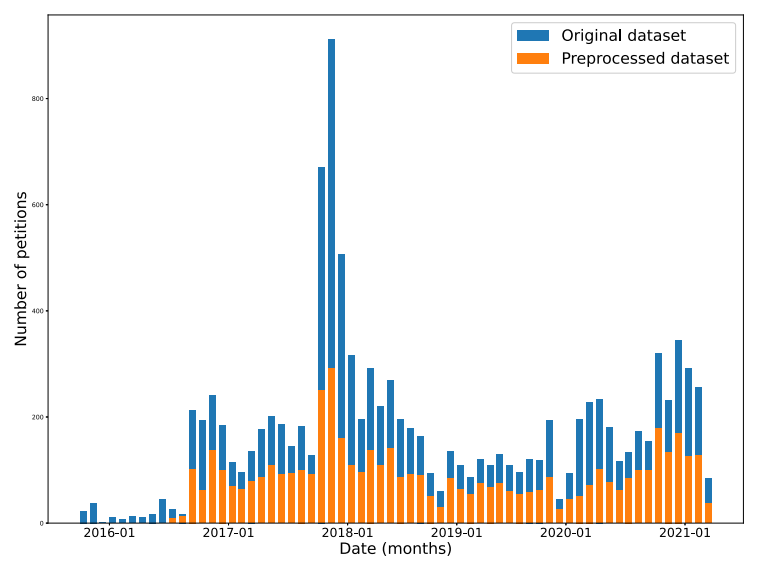

Fig. 3. Proposal frequency on the Join platform over time.

most petitions can only manage to garner very few supporting votes and a few going through the roof. The rule of the threshold set to 5,000 supporting votes clearly manifests itself in the form of a plateau effect. Once the necessary threshold has been reached, further supporting votes are not necessary.

TABLE I

ADDITIONAL STATISTICS ON THE PREPROCESSED DATA

\begin{tabular}{|l|l|l|l|}
\hline & $\begin{array}{l}\text { Not interrupted } \\
\text { by elections }\end{array}$ & $\begin{array}{l}\text { Interrupted } \\
\text { by elections }\end{array}$ & Total \\
\hline Threshold reached & $\begin{array}{l}223 \\
(4.68 \%)\end{array}$ & $\begin{array}{l}8 \\
(2.61 \%)\end{array}$ & $\begin{array}{l}231 \\
(4.55 \%)\end{array}$ \\
\hline Threshold not reached & 4,542 & 301 & 4,843 \\
\hline Total & 4,765 & 309 & 5,074 \\
\hline
\end{tabular}

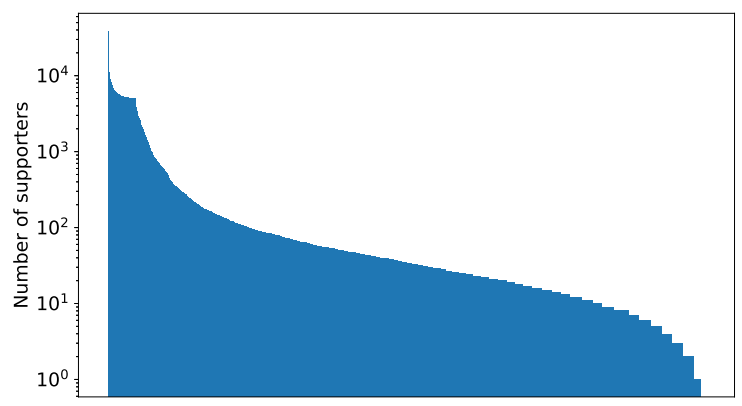

Fig. 4. Number of supporters per petition.

The second kind of data which are used for exploratory analysis are the voting histories for the petitions. The data is available for download at each proposal's individual page on the platform. Neither the aggregated nor the individual data include the beginning and the end dates of the voting period. They can only be checked at the proposal pages. Accordingly, this information had to be retrieved by pattern-matching the scraped html pages of all proposals.

The list of the 10 most successful proposals on the Join platform (see Table II) demonstrates that there are highly active policy proposals for almost every year, and the topical range is broad. Social as well as regulatory policies are among the most popular with the highest support votes on the platform.

TABLE II

Top 10 Most Successful Proposals on JoIN

\begin{tabular}{|l|l|l|}
\hline Date & Topic & Votes \\
\hline $2018 / 07 / 20$ & $\begin{array}{l}\text { Change job title from "Accoun- } \\
\text { tant" to "Tax Official" }\end{array}$ & 39,044 \\
\hline $2017 / 11 / 03$ & $\begin{array}{l}\text { Support "Caning" as a form of pun- } \\
\text { ishment for drunk driving, sexual } \\
\text { assaults, and child abuse criminals }\end{array}$ & 31,750 \\
\hline $2017 / 11 / 13$ & $\begin{array}{l}\text { Increase the age range for childcare } \\
\text { allowance from 0-2 to 0-6 years }\end{array}$ & 17,140 \\
\hline $2018 / 06 / 22$ & $\begin{array}{l}\text { Provide financial support to parents } \\
\text { hiring a babysitter }\end{array}$ & 13,575 \\
\hline $2018 / 03 / 29$ & $\begin{array}{l}\text { Animal shelters should follow-up } \\
\text { on the number of animals adopted }\end{array}$ & 12,903 \\
\hline $2020 / 08 / 28$ & $\begin{array}{l}\text { Doubling childcare allowance for } \\
\text { 0-6 years old }\end{array}$ & 11,306 \\
\hline $2018 / 03 / 07$ & $\begin{array}{l}\text { Prevent printing advertisements on } \\
\text { electronic invoices }\end{array}$ & 11,232 \\
\hline $2018 / 04 / 21$ & Modification of tobacco tax system & 10,710 \\
\hline $2017 / 10 / 25$ & $\begin{array}{l}\text { Childcare subsidy for children 2-5 } \\
\text { years old }\end{array}$ & 10,675 \\
\hline $2020 / 12 / 23$ & Modification of school hours & 10,296 \\
\hline
\end{tabular}

\section{Policy Proposal Example Cases}

In this section the variation of e-petition signature support over time is exemplified by providing some insightful cases extracted from the Join platform open data portal. The selected cases showcase interesting petition signature patterns but are not necessarily the most successful ones.

\section{A. Re-labeling job title for "accountants" to "tax official",} July 2018

The most supported case on the Join platform in the past few years dealt with the name used for tax experts, in Chinese pejoratively called bookkeepers, to the more respectful job title of tax official. According to the Taoyuan City Certified Tax Agents Association in Taiwan, there are approximately 9,000 tax workers managing tax-related work and contributing to the Taiwanese economy. As these tax workers would like society to give them more respect and support, they initiated a respective proposal on the Join platform (see Fig. 5).

The petition support signature dynamics over time show a pattern of reaching the necessary number of online endorsements within a matter of days, continuing a probably professionally organized campaign beyond the necessary and even largely overshooting the threshold for signatures.

\section{B. Elimination of Naphtalene Mothballs, April 2020}

Although the government has already set strict regulations against the usage of naphthalene mothballs in Taiwan, especially in public areas, there are parts of government units, schools, military camps, etc. that are still using them to repel insects and deodorize, which causes a potential danger for the general public, students, military and public education personnel, and government contract personnel, particularly 


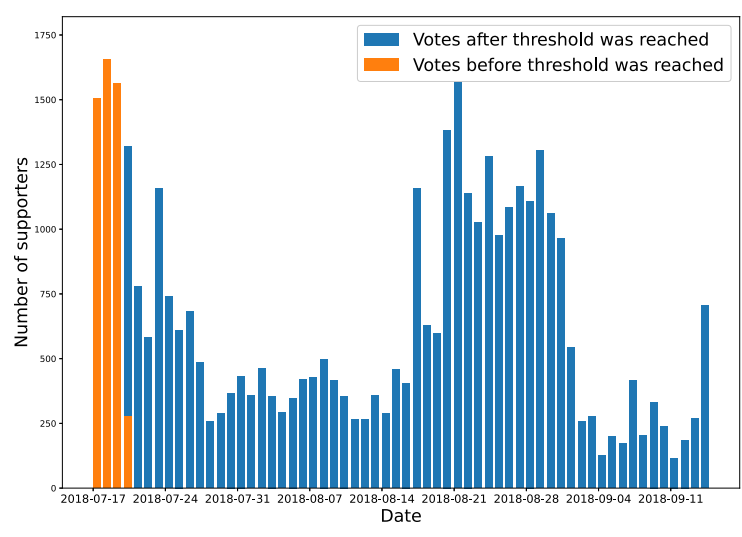

Fig. 5. Supporting Votes Timeline, Accountants Proposal.

individuals with a G6PD deficiency. The proposal is brought up with the expectation for the Taiwanese government to gradually ban the manufacturing, processing, import, sale and use of non-industrial naphthalene (mothball pills) and pdichlorobenzene products within five years.

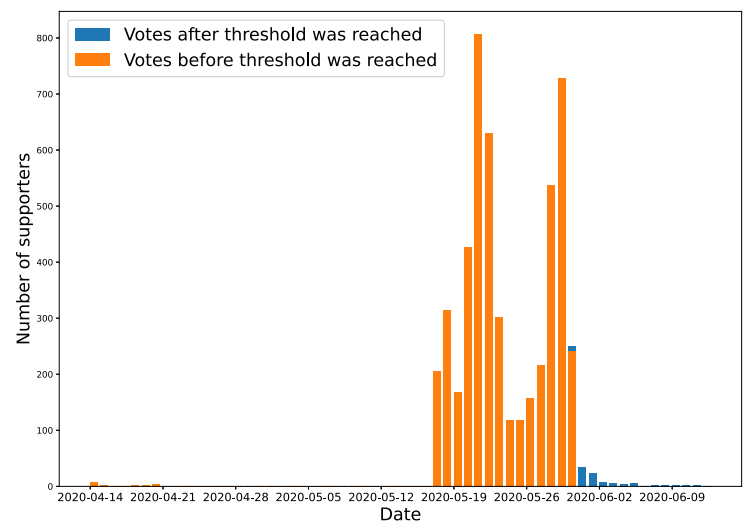

Fig. 6. Supporting Votes Timeline, Mothball Proposal.

As a response, the government agreed to eliminate the use of naphthalene mothballs in public areas to protect the rights, health and safety of patients with G6PD deficiency. The Ministry of Health and Welfare was requested to promote awareness of the G6PD deficiency and to promote awareness of the safety of environmental medicine. In addition, the responsibility of pharmaceutical companies should be strengthened. Naphthalene pill producers were asked to strengthen product packaging warnings and to provide consulting.

Looking at the support vote dynamics within the 60 days period in Fig. 6 we can observe a relatively long period with almost no activity and a seemingly concerted campaign of two weeks towards the end of May 2020 during which the necessary number of support signatures were collected. This is one of the distinctive signature collection dynamic patterns also known from other cases around the globe. Typically, a concerted effort combined with some media coverage leads to more activity ultimately allowing the petition to reach the threshold.

\section{Import of Pork Meat, October 2020}

After the Taiwanese government lifted a ban to import pork from the USA, concerns among domestic meat producers as well as the general public over food safety related to the additive ractopamine, lead to an e-petition on the Join platform. The petitioners asked for a label indicating on the container or outer packaging of imported pork, re-products, mixed products, and food additives whether it contains ractopamine pork. Pork importers who import pork containing ractopamine should list a specific item number for identification. Food labeling and food additives related regulations should be added to indicate whether pork containing ractopamine was used.

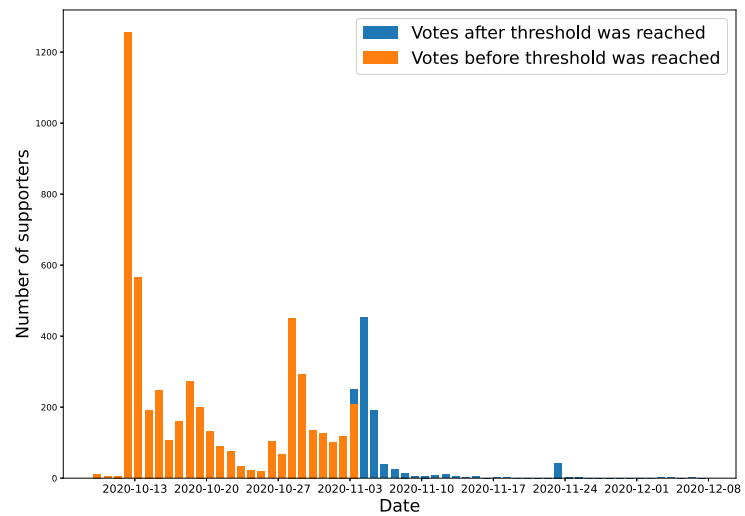

Fig. 7. Supporting Votes Timeline, Ractopamine Pork Proposal.

The government responded as follows. As the amount of ractopamine in imported pork is below the safety allowance, the government will not take into consideration all of the requests in the proposal. However, government has set up an open-source document for citizens to download information about shops that do not sell pork with ractopamine.

The pattern for the supporting votes for this e-petition over time looks different (see Fig. 7). Most e-petition signatures came in right on the first day and in subsequent days, in a rather short time frame, roughly half of the available time frame of the totally available 60 days. Interestingly enough, this petition case seemed to having served as a kind of test bed for the political opposition party to launch the signature collection procedure triggering a national referendum vote. The threshold to initiate a nationwide referendum on this issue was reached and the referendum is scheduled for August 2021.

\section{Modify school class time, 20 December 2020}

Due to the early school time, it is very common for junior high and high school students to not get enough sleep on a daily basis and often doze out during class. Therefore, the proposal suggests the Taiwanese government to modify class time; as the original class time on average in Taiwanese local schools is from 7:30 am to 5:00 pm, the proposer of this case believes it is better to change class time starting from 9:30 am to 5:00 pm. In this way, students will be able to get enough sleep, be able to enhance their studying efficiency, and have better energy and higher learning efficiency. 


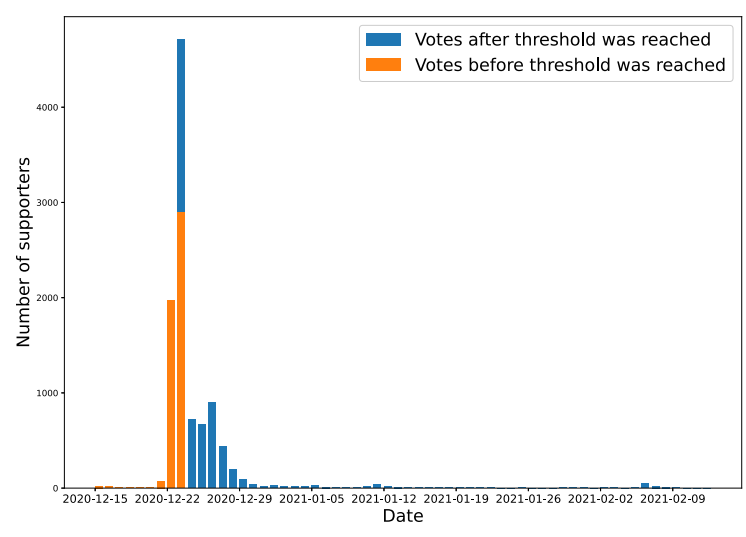

Fig. 8. Supporting Votes Timeline, School Hours Proposal.

This is still an ongoing case. According to the regulations on the Join platform, the Ministry of Education must complete a specific response within two months for this proposal (before February 23, 2021) as it surpasses 5,000 votes. However, as this case was listed as a collaborative topic of the "Opening of Government Liaison Work Promotion Meeting in January, 2021" held by the Office of the Executive Yuan Tang Feng, and it is expected that the sponsor and related personnel will be invited for collaborative discussion on March 6, 2021, the deadline of the detailed response from the government on the Join platform was extended to April 23, 2021.

The signature collection dynamics of this example case (see Fig. 8) demonstrate that popular and easy to understand requests can reach the necessary threshold of supporting votes in a very short time, within a couple of days right from the beginning when launched on the Join platform.

\section{CONCLUSIONS}

Previous empirical studies on online petitions were able to demonstrate that the success of proposals largely depends on the first few days [11]. Online petition support shows a heavy power law distribution with only a few of them garnering a lot of support and many of them not making the threshold or with relatively low numbers of signatures [12]. Once users of online petition platforms are mobilized to engage in online support of a specific proposal there seems to be a high likelihood of a co-signing behavior, namely to sign one or a few other proposals within the same thematic background or by chance being on the same online listing on that particular moment. As a consequence less popular proposals can eventually profit from a windfall gain effect [1]. Furthermore, several studies on issues of digital divide were conducted related to online petition-signing, arguing that the more disadvantaged strata of society are also less likely to become active online petition supporters [13]. However, online petitions are not submitted to a void but to existing societal and political networks. Which digitally submitted policy proposals on the Join are successful also depends on the people with whom an initiative is launched or by whom it is recommended in social media. From the perspective of initiators, promotion via mass media is therefore desirable in order to reach as many people as possible who can establish the connection to more distant clusters of potential supporters in a social network. That again is easier to achieve for well connected political actors such as political parties and interest groups. As demonstrated with a selection of cases in this preliminary outline of petition dynamics on the Join platform in Taiwan, not only the topics and policy types of petitions need to be taken into account but also additional factors such as media coverage as well as political and professional lobbying activities. Annotation of the here presented petition data therefore is the next step on the way to a model of online petition signing dynamics.

\section{REFERENCES}

[1] C. Dumas, T. Harrison, L. Hagen, and X. Zhao, "What Do the People Think?: E-Petitioning and Policy Decision Making," in Beyond Bureaucracy. Public Administration and Information Technology, vol. 25, 2017, pp. 187-207.

[2] U. Serdült, F. Mendez, M. Harris, and H. S. Seo, "Scaling Up Democracies with E-Collecting?" in 2016 Conference for E-Democracy and Open Government (CeDEM), 2016, pp. 25-31.

[3] F. Mendez, R. Zwicky, and D. Kübler, "Taking stock of the European Citizens' Initiative: democratic potential and possible institutional trajectories," in Democratic empowerment in the European Union, F. V. Waarden and D. Levi-Faur, Eds. Cheltenham: Edward Elgar Publishing, 2018, pp. 63-84.

[4] J. Huttunen and H. S. Christensen, "Engaging the Millennials: The Citizens' Initiative in Finland," YOUNG, vol. 28, no. 2, pp. 175-198, 2020. [Online]. Available: https://doi.org/10.1177/1103308819853055

[5] R. Lindner and U. Riehm, "Broadening Participation Through EPetitions? An Empirical Study of Petitions to the German Parliament," Policy \& Internet, vol. 3, no. 1, pp. 1-23, 2011. [Online]. Available: https://onlinelibrary.wiley.com/doi/abs/10.2202/1944-2866.1083

[6] P.-Y. Chu, H.-L. Tseng, C.-P. Lee, W.-L. Huang, T.-Y. Huang, and Y.-T. Hung, "A longitudinal research of public value and electronic governance development in Taiwan," in Proceedings of the 10th International Conference on Theory and Practice of Electronic Governance, 2017, pp. 459-464.

[7] C.-H. TSAO et al., “網路公共參與之議題内容分析-以公共政策網路 參與平台為例 [Analysis of the topic content of online public participation - taking the JOIN platform as an example]," Ph.D. dissertation, National Central University, 2019.

[8] 劉宗喜 and 莊宜貞, “公共政策網路參與 [提點子] 四周年民衆關注 議題研析 [The "idea proposal" function of the JOIN platform - 4th anniversary online participation research and analysis on issue topics]," 政府機關資訊通報, no. 361, pp. 56-67, 2019.

[9] 曹騏祥, 許雲翔, and 廖洲棚, “網路公共參與之議題内容分析-以公共 政 策網路參與平台為例 [Analysis of the public participation platform - take the JOIN platform as an example],”台灣公共行政與公共事 務系所聯合會, Tech. Rep., 2018, accessed 30 May 2021. [Online]. Available: https://tinyurl.com/cy6z3y8d

[10] 國家發展委員會, “107年公共政策網路參與平臺 公民參與情形調查 報告 [Public participation report in 2018 for the JOIN platform]," National Development Council, Tech. Rep., 2018, accessed 31 May 2021. [Online]. Available: https://tinyurl.com/3wruy55v

[11] K. Kitayama, S. Subramanian, and T. Baldwin, "Popularity Prediction of Online Petitions using a Multimodal DeepRegression Model," in Proceedings of the The 18th Annual Workshop of the Australasian Language Technology Association. Virtual Workshop: Australasian Language Technology Association, Dec. 2020, pp. 110-114. [Online]. Available: https://www.aclweb.org/anthology/2020.alta-1.14

[12] L. Böttcher, O. Woolley-Meza, and D. Brockmann, "Temporal dynamics of online petitions," PLOS ONE, vol. 12, no. 5, pp. 1-12, 052017. [Online]. Available: https://doi.org/10.1371/journal.pone.0178062

[13] T. Elliott and J. Earl, "Online protest participation and the digital divide: Modeling the effect of the digital divide on online petition-signing," New Media \& Society, vol. 20, no. 2, pp. 698-719, 2018. [Online]. Available: https://doi.org/10.1177/1461444816669159 